\title{
Modeling of mathematical beliefs of secondary mathematics teachers towards their teaching practices : a structural equation approach.
}

\begin{abstract}
An attitude or a belief can be strong, intense or weak and loose, depending on the provoking situation and the degree of personal involvement and interest. In particular, change in the beliefs of mathematics teachers could occur as a consequences of pedagogical conflict resolution and is influenced by the content and structure of his/her beliefs about mathematics per se (Chapman, 2002). This article describes a study of mathematical values among Malaysian mathematics secondary school teachers by investigating teachers' attitudes towards their instructional practices based on four schools the philosophy of mathematics which are logicism, formalism, intuitionism and kuhnism. This instrument which was developed by the researchers was distributed to mathematics teachers teaching in secondary school in Malaysia and analysed quantitavely. The study indicated that majority of teachers beliefs towards mathematics as kuhnism with instructional practices based on formalism has the highest correlations $(r=0.38)$. These findings imply that majority of mathematics teachers in secondary school emphasized more on symbols and formulas in their teaching. Therefore, more attention should be given towards shifting the thinking of mathematics teachers from mathematics as a value free subject to that of value laden subject.
\end{abstract}

Keyword: Teachers' attitudes; Teaching practices; Mathematical beliefs; Mathematics education. 